\title{
Benefits and Development of Adoption Building Information Models for Construction Management
}

\author{
Mr. Yunhui Yang ${ }^{1, a}$, Ms. Ping Liü $^{2, b}$ \\ Kunming Metallurgy College, Kunming, China \\ a309124927@qq.com, b1059140543@qq.com
}

\begin{abstract}
Keywords: BIM, Construction Management, Constructability Review, Contractor, Prefabricate, Cost Estimate

Abstract. Building Information Modeling is a revolutionary technology and process that has transformed the ways projects are designed, analyzed, constructed, and managed. BIM is becoming a better known established collaboration process in the construction industry. There are many advantages for using BIM from the pre-construction through the post-construction phase in the construction industry, such as increased building performance, reduced financial risk, reduced project schedule, reliable and accurate cost estimates, program compliance, optimized facility management and maintenance. This paper tries to identify the current uses of BIM in the construction management of developed countries and China, the research was conducted through literature review, case studies, and interviews.
\end{abstract}

\section{Introduction}

1) BIM Application in Construction Management

Construction has evolved through new technologies, adoption of new methods, and maturity of management skills. There is a great trend that is driving the changes in the construction industry which is not only re-shaping the design and construction industry, but also the construction management education. Building Information Modeling (BIM) is the most effective technology that contributes to further developing and enhancing the construction management process. Cost, schedule, productivity, and facility management are the major areas that have direct correlation to the use of BIM visual simulation technology. BIM usage is accelerating powerfully, driven by major private and government owners who want to institutionalize its benefits of faster, more certain project delivery, and more reliable quality and cost. Owners are increasingly requiring BIM services from contractors, architects and engineering firms. Many top companies, as well as mid-size companies, have now adopted BIM for their construction management globally. The more deeply that construction companies become engaged with BIM, the greater their ability to receive its benefits and to realize very strong return on their investments in BIM.

2) BIM Adoption in Global Construction Industry

BIM is not only a technological innovation, but also a significant shift in the overall construction management process, it is growing fastest among contractors. Many construction firms are now investing in BIM technologies during bidding, preconstruction, construction and post construction. Contractors are increasingly showing leadership in driving BIM innovation, metrics and value, contractors now appear to be edging ahead of architects in implementation globally.

The most recent McGraw-Hill Smart Market Report found that "71\% of contractors report positive results with the use of BIM", the report showed that contractors are adopting and using BIM faster than any other group in the industry, level of BIM adoption in North America was 28\% in 2007. It increased to $49 \%$ in 2009 and to $71 \%$ in 2012, revealing dramatic surge from 2007 to 2012, and the U.K. and other regions are poised for similar dramatic expansions. Japanese, German and French contractors report the top ROI on BIM investments, with South Korea, the UK and the US trailing all regions. Although BIM is not yet widely used in China, BIM implementation in Chinese architects and contractors who are currently using BIM indicates that they are planning to greatly increase their level of BIM implementation, with a forecast of $108 \%$ growth, China is among the top five fastest-growing BIM regions surveyed by Dodge Data \& Analytics for contractors who will be doing more than $30 \%$ of their work in BIM two years from now. 
Nowadays, trade contractors with good BIM skills are critical in order to continue to strengthen China's technological capability in model-based construction, which is a fast-growing BIM trend throughout the world. Over half of Chinese general contractors believe strongly that trade contractors having BIM skills will reduce project cost and duration, and increase innovation, project quality and contractor profit. BIM has been used throughout these projects: Shanghai Tower, the tallest and most sustainable skyscraper in China, the iconic Z15 Tower in Beijing, Shanghai Disneyland Resort etc. to improve efficiency, reduce errors and streamline collaboration among large and diverse project teams.

\section{Benefits of BIM adoption for construction management}

With BIM-based construction management processes, the project team increases the value of project information, improves the efficiency of team collaboration. It implies that not only is the overall project productivity is increased but also cost and time are saved to reduce rework. The project team can find optimized management techniques by exporting relevant BIM data to improve the processes of construction management and get greater returns on their investments. The benefits of BIM adoption in construction management are as follows:

1) Sustainability Evaluation

Sustainability evaluation is a process in which a green building is evaluated based on sustainable criteria to assess if all materials, performance and process of the sustainable features have been archived by means of BIM simulation. The key benefit of BIM is its accurate geometrical representation of the parts of a building in an integrated data environment and that can be used to analyze its performance. Sustainability evaluations will be applied across all four phases of a construction project, planning, design, construction, and operation. BIM simulates all sustainable aspects of a project throughout its life-cycle in order to obtain the desired sustainability analysis including energy, lighting, and mechanical can be used to measure building's performance. Sustainability evaluation is most effective when it is done in planning and design stages and then applied in the construction and operations phase, which will greatly improve communication between project participants. Moreover, sustainability evaluation will align scheduling and material quantities tracking for more efficient material use and better cash flow analysis by means of BIM model to support green certifications such as LEED in the USA.

2)Constructability Review

If contractors want to implement management activities well, they need to identify the potential problems from initial designs before the construction. Using BIM tools, the project teams can perform detailed constructability analysis to plan sequence of operations at the jobsite. Since there are many questions that need to be addressed and planned in the preconstruction phase for site coordination, such as looking at various sequencing options, site logistics, hoisting alternatives and costs. Simulation by means of BIM platform in architectural and engineering projects is to validate designs created by individual domain experts and check potential design problems easily, and is usually performed on reduced-complexity system models in order to contain the overall analysis time and cost. The use of BIM especially enhances the collaborative efforts of the project team. The architect and engineer can test their design ideas; the contractor can provide constructability, sequencing, value and engineering reports, and can start 3D coordination between subcontractors and vendors during early stages of design. Overall, the BIM promotes the collaboration of all of the projection participants for constructability review because data is consist.

3) Mobilizing Visualization

BIM is a great visualization tool which provides a three dimensional virtual representation of the building for better understanding of what the final project may look like, thus project team can substantially reduce errors and omissions in construction documents in advance of execution. Utilizing BIM 3D or 4D site coordination models in the preconstruction can plan for site logistics, develop traffic layouts, and identify potential hazards at the jobsite which can aid in preparing a more realistic site safety plan and construction waste disposal plan. During the design phase, the use of BIM can maximize its impact on a project since the ability to influence cost is the highest. A 
virtual mock up is cost efficient in comparison to a physical mock-up. During the bidding phase of the project, the contractor can provide renderings, walkthroughs, and sequencing of the model to better communicate the BIM concept in 3D or 4D modeling. The project team can creatively come up with ideas and provide solutions to issues before problems become high cost impacts to the project, thus, the site mobilization can be done in a more efficiently way.

4)Multi-Dimensional Coordination

Collaboration of the construction team with the architect, engineer, contractor and the owner is of great important to be started on early stages of construction management. BIM and web-based project management software has created a solid platform for an improved, more efficient means of collaboration between all the parties involved in the project. BIM carries all the information related to the building, including physical and functional characteristics and project life cycle information. The BIM virtual mock ups help to communicate and collaborate among the project participants. The coordination efforts of the project participants in advance of construction help to reduce design errors tremendously and to better understand ahead of time the work to be done, BIM helps to timely modify designs to eliminate or reduce MEP conflicts by promoting collaboration of information exchange between the subcontractors, thereby reducing costs, delivery time and environmental impact as well as improving communication, productivity and quality.

The 3D coordination can ensure that any same space interference or clearance clash conflicts are resolved automatically. When coordinating constructions sequencing by integrating schedule data with the model data (4D) to quantify materials and apply cost information (5D) to animate construction progression and improve all of these processes, the project team can analyze on-site material problems, develop phasing plans, improve the sequencing of trade contractors/subcontractors or analyze the cost of construction delays. Cost can also be attached to drawing elements that represent building systems for estimating and value engineering. The owner, architect, engineer and contractor can eliminate some of the coordination issues via BIM, the subcontractors can provide more detailed shop and fabrication drawing and coordinate the approval process of the shop drawings.

5) Prefabrication or Pre-manufacture

Prefabrication requires design and field accuracy to perform work more precisely, and less costly in a shorter period of time. Digital prefabrication techniques blur the distinction between design and production. As BIM can provide the required level of accuracy by including the specifications, sequence, finishes, and the 3D visual for each component. Contractors usually must plan for coordination, shop drawings approval, fabrication, transportation, and installation times. Once the details are approved, the products can be fabricated using computer numerical control machines. Thus, it gives rise to extensive prefabrication, mass customization, and factory-produced building components by means of BIM data.

Digitally prefabricated building components further reduce the pressure on field construction productivity, reduce field labor cost and time, and increases accuracy in a good quality construction. Difficult electrical, plumbing (MEP) including hot, cold, drain/vent, vacuum etc. components, steel elements connections generated in BIM can be manufactured offsite to save time and money. Providing BIM models to building product manufacturers to prefabricate building elements off-site also offers many green benefits, including time saving, cost saving and the reduction of waste produced by onsite fabrication.

6) Construction Planning

The construction planning involves the scheduling and sequencing of the model to coordinate virtual construction in time and space. BIM based scheduling can be used for quick or more detailed sequencing. 4D modeling is a powerful visualization and communication tool that can give the project team a better understanding the scheduling of project milestones and construction plans. The planning through using BIM enhances site utilization, space coordination, and product information. A 4D model can either include a site logistics plan or a virtual tools to visually depict the space utilization of the job site including the site utilization consists of lay down areas, site work progress, and location of trailers and equipment and hoist assembly, and temporary components such as 
cranes, trucks, fencing etc.

Using BIM tools through visualization and communication will optimize management control of the specific task in the schedule for the purpose of informing critical planning decisions and construction methods, site space utilization, resource allocation, activity sequencing. A detailed BIM based schedules can be used for more accurate visualization, better construction planning. During construction the BIM tools will also be utilized to facilitate activity scheduling.

7) Construction Monitoring

Construction monitoring is an extremely important part of the execution management. Throughout the construction period, the project teams will continuously update the BIM models and monitor repetitive tasks during construction progress, so that it will reflect the most up-to-date information. There are several field data acquisition systems that can be used with 4D BIM to keep track of the progress of the construction. Radio frequency identification and 3D laser scanning can be used to keep track of the material delivery status and monitor the workforce. The laser scanning can be a good process to identify the current location and status of building components, 3D laser scanning can be used to monitor the progress of designed building information model, and the scanned as-built data can be manually checked against the original designed model to detect any deviations. Overall, construction planning and monitoring with 4D BIM is a great process to build a facility as per the designed model. The project participants can use various 4D BIM enabled tools to enhance the quality control process.

8) Construction Safety

BIM offers several benefits that can improve construction safety, 4D BIM can be used as a visualization tool to identify the safety features that will be required at different times. Once the model is used as a planning tool for safety, the 4D model can be used to monitor the safety precautions taken at the jobsite. BIM can be used to help subcontractors perform job hazard analysis and develop safe work methods. Overall, 4D BIM can be used a proactive approach to enhance the planning and monitoring of the jobsite safety. Furthermore, as BIM reduces the incidence of coordination problems and rework, it also improves safety.

The site-specific safety plan helps to identify and eliminate a project's potential hazards. Pre-task planning offers the most opportunities to use BIM for construction safety management. Based on these observations, the temporary safety related structures such as rails and fences can be modeled in the BIM and the safety related activities can be integrated into the schedule. Accident investigation BIM can be used during an incident investigation to recreate event sequence and the incident scene. However, research has shown that industry practitioners perceive BIM has limited effect on safety, therefore, safety professionals should encourage team members to use BIM for safety and educate them on how to look for safety concerns during the BIM review process.

9)Cost Management

Cost estimating requires the expertise of the cost estimator to analyze the components of a material and how they get installed. Accuracy of estimates is a serious issue, hence built-in estimation features in BIM software can significantly improve the accuracy of cost the estimates. By means of BIM intelligent and multi-dimensional objects which contain information about quantity and specification details enables automatic quantification and the production of schedules, which will largely eliminate the need for manual quantity take-off of buildings during estimating. Thus, cost estimating can be carried out through the 5D function, by linking the model to an estimating database, and avoided the time consuming and duplicate process of estimators quantifying what designers have already produced. The cost schedules such as Bill of Quantities (BOQ) and the cost plans can be automatically and speedily generated according to measurement rules and cost.

The speedy, accurate and detailed information access BIM enables cost managers to compare alternative design solutions for determining better value for the owner. As the estimating information is available, any subsequent process like cost and financial reporting and monitoring processes that rely on this information can also be improved in terms of speed and accurate. Through automatic quantification, human error and inaccurate drawing interpretation during measurement will be eliminated. The ability to predict and control costs more effectively through 
BIM reduces the chance of unanticipated cost overruns and helps a project stay on budget. More sophisticated users of BIM have the ability to actually reduce a project's construction cost through model-driven processes like prefabrication and by applying lean principles that are facilitated through BIM. However, although BIM makes a lot of time and labour intensive tasks automated, there is still the need for professional input required for making assumptions and assessments.

\section{Challenges of BIM Application}

Building Information Modeling is of great beneficial to construction industry. Various BIM tools have provided more and more time and cost savings benefits and yielded better quality construction products, but BIM tools are not perfect and need further improvements presently. Therefore, the use of BIM tools can be challenging in construction management activities.

1)Multi-dimensional modeling is an extremely powerful construction planning application for the construction management team, but interoperability of BIM tools offered by market presently requires further review by the construction industry.

2)BIM based scheduling can be very powerful for detail oriented planning and controlling of the projects, but the schedule updating can be costly and time consuming. BIM software providing the synchronization of the updated models and schedules, the setbacks such as interoperability of BIM files, and the generation of elements under resources based on specific locations need further improvements.

3)Although BIM software provides a better chance to detect the clashes in the built model automatically for virtual coordination, a senior and experienced engineer still must join and identifies the real potential conflict problems during virtual simulation testing.

4) BIM is great concept and practice, some executives of construction firms are highly concerned with the confidentiality of project information. Therefore, concentrating project data into centralized models presents a perceived security risk, which will need to be addressed.

\section{Conclusion}

BIM tools are becoming widely adopted for building sustainability evaluation, constructability review, coordination and collision detection, construction planning and monitoring, prefabrication, cost estimating, safety management, and facilities management in construction execution. In addition, building performance and predictability of outcomes have been greatly improved by adopting BIM. The use of BIM accelerates collaboration within project teams will lead to improved profitability, reduced costs, better time management and improved customer/owner relationships. Early involvement of all the project participants is extremely important for a successful BIM collaborative process. As the construction industry addresses the setbacks of BIM tools, the benefits of BIM will be mostly optimized in the future. In a long-term view, the BIM technology will be the technology fusion in construction industry which can make higher productivity through the reducing of materials, times, and costs of the construction.

\section{Reference}

[1] Niraj Thurairajah PhD, Dan Goucher BSc, Advantages and Challenges of Using BIM: a Cost Consultant’s Perspective, 49th ASC Annual International Conference Proceedings, 2013.

[2] Sathy Rajendran and Brian Clarke, Building Information Modeling safety benefit \& Opportunities Professional Safety, 2011.

[3] Hu Z. and Zhang J., BIM- and 4D-based integrated solution of analysis and management for conflicts and structural safety problems during construction: 2. Development and site trials, Automation in Construction, Vol. 20(2), pp. 167-180, 2011

[4] Sacks, R. Requirements for building information modeling based lean production management systems for construction, Automation in Construction, 19(5), pp. 641-655. (2010). 
[5] Nassar, K., The Effect of Building Information Modeling on the Accuracy of Estimates. Paper presented at the 46th ASC Annual International Conference, Boston, Massachusetts, (2010)

[6] Adopting BIM for facilities management Solutions for managing the Sydney Opera House, First published 2007 by Cooperative Research Centre for Construction Innovation, for Icon.Net Pty Ltd.

[7] The construction enterprise BIM technology application present situation research report 2014, New Luban magazine, 2014.

[8] Business Value Of BIM In Global Markets 2014-Smart Report.

[9] The Business Value of BIM in China, SmartMarket Report 2015.

[10] Collins, Ronan. BIM for Safety, Virtual Design and Construction VDC Application. Intelibuild, Web. March 2011.

[11] Hajian, Hamid, and Burcin Becerik-Gerber. A Research Outlook for Real-time Project Information Management by Integrating Advanced Field Data Acquisition Systems and Building Information Modeling. University of South California. Sept. 2009. Web. July 2010 